\title{
CURVAS DE RENDIMENTO DA EXTRAÇÃO MECÂNICA E CARACTERIZAÇÃO DO ÓLEO DE PINHÃO MANSO
}

\author{
B. K. S. A. ANDRADE ${ }^{1}$, J. I. SOLETTI ${ }^{1}$, S. H. V. de CARVALHO ${ }^{1}$ \\ ${ }^{1}$ Universidade Federal de Alagoas, Departamento de Engenharia Química \\ E-mail para contato: bazkarolinne@gmail.com
}

\begin{abstract}
RESUMO - O pinhão manso (Jatropha curcas L.) é uma planta com alto teor de óleo, resistente e perene. Essas características tornam-o uma matéria-prima promissora para produção de biodiesel. Desta forma, este trabalho tem como objetivo estudar o processo de extração mecânica do óleo de pinhão manso. $\mathrm{Na}$ extração mecânica, $200 \mathrm{~g}$ de semente foram prensadas à pressões de 165, 247,5, 330 , e $495 \mathrm{kgf} / \mathrm{cm}^{2}$. O processo de extração foi analisado em função do tempo. A pressão de $495 \mathrm{kgf} / \mathrm{cm}^{2}$ foi a mais eficiente em termos de rendimento $(76,51 \%)$. Foram obtidas as curvas de extração do processo. A caracterização do óleo de umidade, densidade e índice de acidez apresentou os valores acima do permitido pela ANP.
\end{abstract}

Palavras-chaves: Pinhão manso, prensagem, extração, óleo, caracterização.

\section{INTRODUÇÃO}

Com a busca de fontes renováveis de energia e o advento do biodiesel, surgiram pesquisas relacionadas a diversas plantas oleaginosas. Dentre elas, aponta-se o pinhão manso (Jatropha curcas) como uma alternativa por ser uma fonte rica em óleo, pela facilidade de cultivo e pelo custo mais barato que a soja, o milho e o trigo.

A semente do pinhão manso possui um teor de óleo de aproximadamente $38 \%$, sendo, portanto, uma oleaginosa com grande capacidade de produção de óleo, maior, inclusive que a soja (18\%), matéria-prima mais utilizada atualmente para produção de biodiesel (SAUER, 2006).

\subsection{Extração Mecânica}

A extração do óleo, a depender da quantidade de óleo contida na oleaginosa, pode ser realizada através da prensagem. É o método mais antigo, recomendado para grãos ricos em óleos (CORREIA, 2009). É um sistema facilmente adaptável a diversos tipos de oleaginosas, bastando para isso alguns simples ajustes mecânicos, e todo o processo de expulsão do óleo é contínuo e feito em um curto espaço de tempo (DUARTE et al., 2011).

Não é necessário o uso de produtos químicos sendo bem mais seguro, pode ser instalado em pequenas propriedades rurais. Além de permitir o uso do subproduto da extração mecânica, torta rica em proteína, como adubo e ração animal no caso do pinhão esta deve ser desintoxicada (DUARTE et al., 2011). A prensa é alimentada com a oleaginosa que sofrerá 


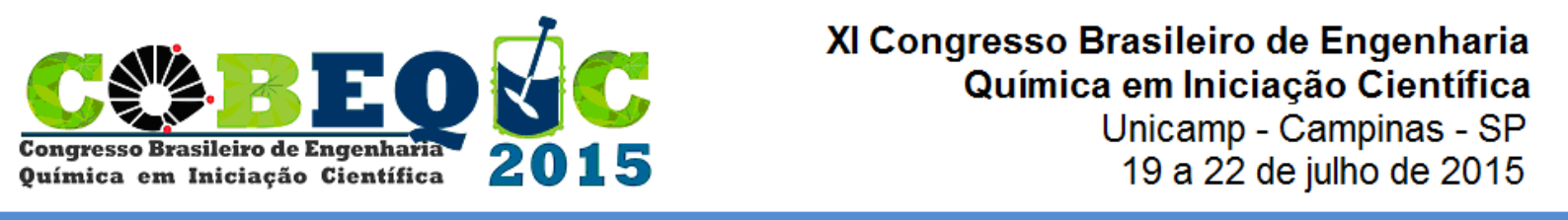

uma alta pressão a qual provoca a ruptura das paredes celulares permitindo que os glóbulos de óleo escapem (CORREIA, 2009).

\subsection{Caracterização do óleo}

A umidade do óleo é definida como sendo o valor percentual de água não combinada na amostra. Um óleo com baixo percentual de umidade apresenta melhor qualidade, maior durabilidade e viscosidade (VIEIRA, 1994).

A densidade de uma substância é a relação existente entre o peso de um determinado volume de matéria e o peso de igual volume da água por unidade de volume a $25^{\circ} \mathrm{C}$ e é aplicável a todos os óleos e gorduras líquidas (FERNANDES, 2010).

O índice de acidez é o número de hidróxido de sódio ou potássio, em mg, necessário para neutralizar os ácidos livres presentes em um grama de óleo ou gordura (FERNANDES, 2010). Procura-se utilizar óleos com baixo valor de índice de acidez, isto porque, ácidos graxos livres podem reagir com o catalisador formando sabões que dificultarão a separação do produto processado (SILVA, 2006).

O objetivo deste trabalho é avaliar o rendimento de óleo obtido a diferentes pressões $\left(165,247,5,330\right.$, e $\left.495 \mathrm{kgf} / \mathrm{cm}^{2}\right)$ da extração em uma prensa hidráulica batelada da marca Tecnal e a caracterização do óleo extraído.

\section{METODOLOGIA}

\subsection{Extração Mecânica}

Cerca de $200 \mathrm{~g}$ de pinhão manso foram transferidos para o vaso cilíndrico da prensa. A amostra foi submetida a uma determinada pressão, a qual foi mantida durante o tempo préestabelecido de 25 minutos. O óleo extraído foi recolhido em uma proveta e pesado ao longo da extração. $\mathrm{O}$ cálculo do rendimento foi obtido em relação à massa de semente seca utilizada na extração. O processo foi realizado em triplicata para as pressões de 165, 247,5, 330, e 495 $\mathrm{kgf} / \mathrm{cm}^{2}$.

\subsection{Caracterização do óleo}

Na caracterização foram determinadas: a umidade, a densidade e o índice de acidez.

A umidade foi determinada pelo método da secagem direta segundo Correia (2009). Foi pesado $5 \mathrm{~g}$ de óleo em uma cápsula de porcelana a qual foi aquecida em estufa por três horas à $105{ }^{\circ} \mathrm{C}$ e pesada novamente. O processo foi repetido até peso constante. Foram feitas triplicatas. Obtida através da Equação 1.

$$
U=\frac{100 \times \mathrm{N}}{\mathrm{P}}
$$


A densidade relativa foi determinada utilizando a norma ABNT NBR 7148/2013 conforme método do densímetro, utilizando o densímetro digital DMA 35N EX Petrol da Anton Paar. O equipamento foi calibrado com etanol e, em seguida, a célula foi preenchida com o óleo a $20^{\circ} \mathrm{C}$ para a leitura da densidade.

A determinação do índice de acidez foi realizada com base no procedimento da American Oil Chemists' Society. Foi utilizado o método AOCS Cd 3d-63 (AOCS, 1993) no qual $5 \mathrm{~mL}$ de óleo são diluídos em uma solução álcool: éter etílico (1:1). A solução foi titulada com $\mathrm{NaOH} 0,01 \mathrm{M}$, utilizando fenolftaleína como indicador.

Com o valor de $\mathrm{NaOH}$ gasto na titulação calculou-se o índice de acidez segundo a equação 2.

$$
A c=\frac{\mathrm{V} \times \mathrm{f} \times 5,61}{\mathrm{P}}
$$

\section{RESULTADOS}

\subsection{Extração Mecânica}

A extração gerou curvas do volume de óleo obtido em função do tempo conforme mostra a Figura 1.

Figura 1 - Curvas do volume de óleo extraído versus o tempo de extração em função da pressão.

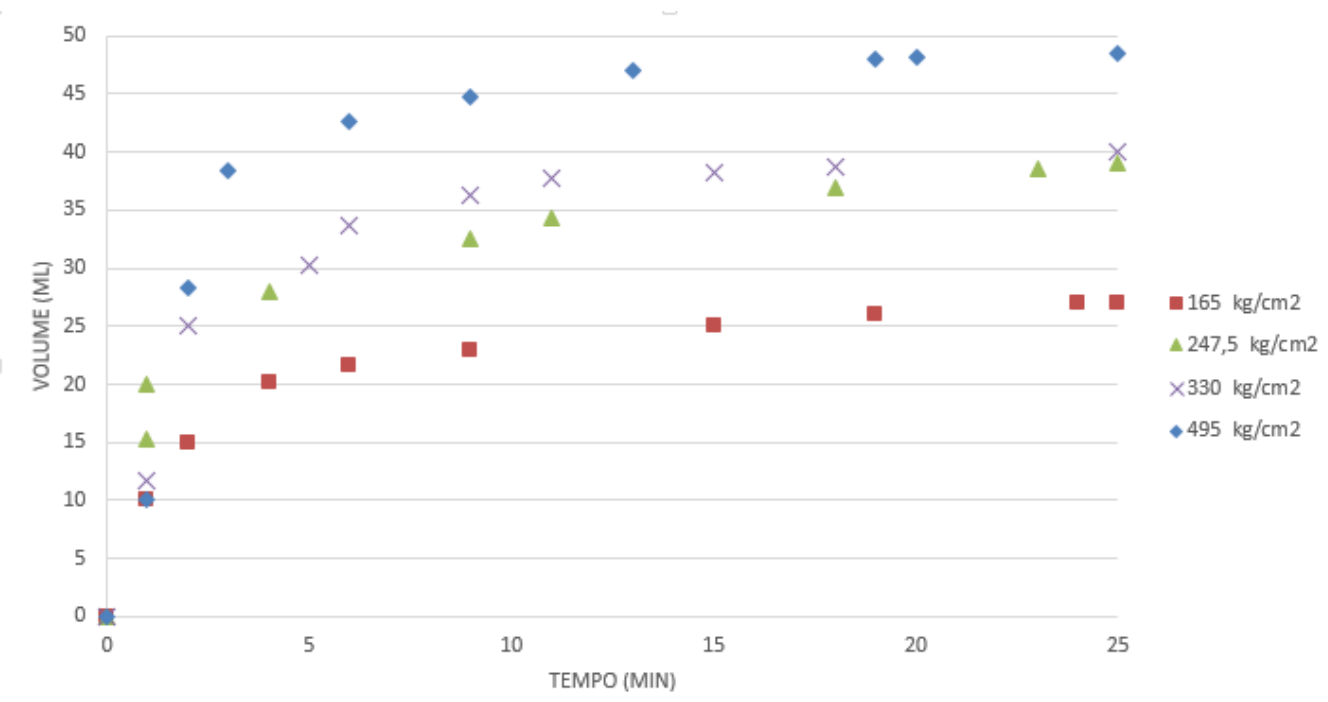

É possível observar que o volume apresentou crescimento acelerado até os cinco minutos, a partir daí foi lento até o início da estabilização aos 15 minutos. Isso ocorre devido à menor massa de óleo presente na amostra ao longo da extração. Para pressões de 165 e $247,5 \mathrm{kgf} / \mathrm{cm}^{2}$ extraiu-se, respectivamente, $27 \mathrm{~mL}$ e $39 \mathrm{~mL}$ de óleo para $200 \mathrm{~g}$ de semente. Para 330 e $495 \mathrm{kgf} / \mathrm{cm}^{2}, 40 \mathrm{~mL}$ e $48 \mathrm{~mL}$, respectivamente. O volume de óleo extraído aumentou com a elevação da pressão. 
Os rendimentos obtidos na extrações mecânicas apresentam-se na Tabela 1.

Tabela 1- Rendimento das extrações mecânicas em função da pressão.

\begin{tabular}{cc}
\hline Pressão $\left(\mathrm{kgf} / \mathrm{cm}^{2}\right)$ & Rendimento $(\%)$ \\
\hline 165,0 & $43,16 \pm 1,73$ \\
247,5 & $57,10 \pm 1,42$ \\
330,0 & $64,47 \pm 0,97$ \\
495,0 & $76,51 \pm 1,78$ \\
\hline
\end{tabular}

O aumento na pressão resultou na elevação do rendimento. Em uma pressão de 495 $\mathrm{kgf} / \mathrm{cm}^{2}$ o rendimento foi $12 \%$ superior ao de $330 \mathrm{kgf} / \mathrm{cm}^{2}$ e $33 \%$ em comparação à 165 $\mathrm{kgf} / \mathrm{cm}^{2}$. Pois o aumento da pressão sobre as sementes causa uma maior compressão nos glóbulos oleaginosos levando à maiores rupturas nas células responsáveis pela melhor extração do óleo. A margem de erro foi calculada com um intervalo de confiança de $95 \%$.

A eficiência efetiva $\left(\eta_{\text {efetiva }}\right)$ da prensagem a qual determina a eficiência da extração mecânica considerando as perdas no equipamento foi calculada segundo a Equação 3.

$$
\eta_{\text {efetiva }}=\frac{M_{\text {óleo }}}{M_{\text {amostra }}} \times 100
$$

A Tabela 2 apresenta os valores das eficiências para as quatro pressões utilizadas na extração.

Tabela 2 - Eficiências em relação à pressão

\begin{tabular}{cc}
\hline Pressão $\left(\mathrm{kgf} / \mathrm{cm}^{2}\right)$ & Eficiência $(\%)$ \\
\hline 165,0 & 11,84 \\
247,5 & 17,77 \\
330,0 & 18,05 \\
495,0 & 21,73 \\
\hline
\end{tabular}

A eficiência da extração foi maior com o aumento da pressão, sendo mais eficiente com $495 \mathrm{kgf} / \mathrm{cm}^{2}$. A extração mecânica, de forma geral, apresentou baixa eficiência, possivelmente decorrente do óleo remanescente na torta, o qual o processo não conseguiu extrair, e da perda para o equipamento.

\subsection{Caracterização do óleo}

A umidade determinada segundo o método da secagem direta apresentou os seguintes valores para a triplicata apresentada na Tabela 3.

Tabela 3 - Umidade do óleo

\begin{tabular}{cc}
\hline Ensaio & Umidade (\%) \\
\hline 1 & 0,449
\end{tabular}




\begin{tabular}{cc}
2 & 0,430 \\
3 & 0,423 \\
\hline Média & 0,434 \\
\hline
\end{tabular}

A média dos valores obtidos nos ensaios forneceu uma umidade de $0,434 \%$. Foi o dobro da permitida segundo a Resolução ANP 045/2014 (0,2\%). A presença de água promove reações de saponificação, além de reduzir a alcalinidade do catalisador o que acarreta em rendimentos mais baixos. É necessário que o óleo passa por um processo de degomagem.

A densidade do óleo foi analisada em triplicata pelo densímetro DMA 35N Petrol conforme Tabela 4.

Tabela 4 - Densidade do óleo

\begin{tabular}{cc}
\hline Ensaio & Densidade $\left(\mathrm{g} / \mathrm{cm}^{3}\right)$ \\
\hline 1 & 914,7 \\
2 & 914,4 \\
3 & 914,3 \\
\hline Média & 914,5 \\
\hline
\end{tabular}

A densidade média do óleo de pinhão manso é $914,5 \mathrm{~g} / \mathrm{cm}^{3}$. É bem maior que o limite permitido pela Resolução ANP 045/2014 de 850 a $900 \mathrm{~kg} / \mathrm{m}^{3}$.

O índice de acidez do óleo dispõem-se na Tabela 5.

Tabela 5 - Índice de acidez do óleo

\begin{tabular}{cc}
\hline Ensaio & Índice de acidez $(\mathrm{mg} \mathrm{KOH} / \mathrm{g}$ óleo $)$ \\
\hline 1 & 13,998 \\
2 & 13,933 \\
\hline Média & 13,965 \\
\hline
\end{tabular}

A acidez é 13,965 mg KOH/ g óleo que é considerada muito alta visto que a segundo a Resolução ANP 045/2014 determina-se um valor máximo de 0,5 mg de KOH/g.

É impróprio para a produção de biodiesel, causaria a não separação de fases e haveria maior consumo de catalisador, uma vez que este atuaria na redução dessa acidez levando à reações de saponificação. Logo, o processo não seria catalisado eficientemente sendo necessário um pré-tratamento e purificação antes da utilização.

\section{CONCLUSÕES}

A metodologia proposta permite avaliar, para diferentes pressões, a percentagem de extração da oleaginosa e assim, calibrar os equipamentos prensas, que possibilite a extração com maior eficiência. O rendimento da extração aumentou com a elevação da pressão. Foi obtida uma melhor extração do óleo quando utilizado $495 \mathrm{kgf} / \mathrm{cm}^{2}$, cerca de $76 \%$. 
Por fim, a caracterização do óleo mostrou que a umidade, a densidade e o índice de acidez estão muito elevados. A utilização do óleo bruto de pinhão manso não permite uma condição ideal para a produção de biodiesel.

\section{NOMENCLATURA}

$\mathrm{M}_{\mathrm{amostra}}$ - Massa da amostra de pinhão manso

$\mathrm{M}_{\text {óleo }}$ - Massa de óleo extraído

$\mathrm{U}$ - Umidade ou substâncias voláteis a $105^{\circ} \mathrm{C}$

$\mathrm{N}$ - Diferença entre a massa inicial e a final $(\mathrm{g})$

$\mathrm{P}$ - Massa da amostra.

Ac - Índice de acidez (mg de $\mathrm{KOH} / \mathrm{g}$ de óleo)

$\mathrm{V}$ - Volume de $\mathrm{NaOH}$ gasto na titulação $(\mathrm{ml})$

$f$ - Fator de correção da solução

5,61 - Equivalente-grama do $\mathrm{KOH}$

$\mathrm{P}$ - Peso da amostra $(\mathrm{g})$

\section{AGRADECIMENTOS}

Ao laboratório LASSOP que deu suporte para que a pesquisa fosse realizada e aos professores João Inácio Soletti, Sandra Helena Vieira de Carvalho e Dayana de Gusmão Coêlho pela orientação.

\section{REFERÊNCIAS}

AMERICAN OIL CHEMISTS' SOCIETY. Official methods and recommended practices. 4. ed. Champaign, 1993. v. 3.

CORREIA, I. M. S.; Extração e Pirólise do Óleo de Girassol (Helianthus annus L.) visando a Produção de Biocombustíveis. Universidade Federal do Rio Grande do Norte, 2009.

DUARTE, E. C. M., BARROS, L. L. S. de, MACIEL, P. B.; Semente, Óleo E Biodiesel De Pinhão Manso (Jatropha Curca, L.): Nutrientes E Elementos Potencialmente Tóxicos Determinados Por Espectroscopia De Massa Com Plasma Acoplado Indutivamente. Trabalho de conclusão de curso de graduação de Tecnologia de Biocombustíveis. Faculdade De Tecnologia Piracicaba - FATEC, 2011.

FERNANDES, J. D.; Análise Técnica e Econômica da Adubação Mineral e Orgânica sob o Cultivo da Mamona e do Pinhão Manso. Tese De Doutorado - Universidade Federal De Campina Grande, Paraíba, 2010.

SAUER, I. L.; QUEIROZ, M. S. de; MIRAGAYA, J. C. G.; MASCARENHAS, R. C.; QUINTINO JÚNIOR, A. R. Energias renováveis: ações e perspectivas na Petrobras. Bahia Análise \& Dados, Salvador, v. 16, n. 1, 2006.

SILVA, C.F. Modelos matemáticos para o processo de transporte de massa na extração de produtos naturais de matrizes sólidas utilizando $\mathrm{CO} 2$ supercrítico: estudo experimental 
e teórico. Dissertação (Mestrado em Ciência de Alimentos) Programa de PôsGraduação em Ciência de Alimentos, Universidade Federal do Rio de Janeiro, 2006.

VIEIRA, F. F. Análise de óleos vegetais. Campina Grande: UEPB, 1994, 45 p. 